\title{
Composite Metal-Matrix Alloys Based on Ni-Al for Obtaining Wear-Resistant Coatings by Electric Spark Deposition
}

\author{
S.N. Khimukhin ${ }^{1}$, S.V. Nikolenko ${ }^{1}$, L.A. Konevtsov ${ }^{1}$, and E.D. Kim ${ }^{2, *}$ \\ ${ }^{1}$ Institute for Materials Technology, Khabarovsk Research Centre at the Far Eastern Branch of the \\ Russian Academy of Sciences, Khabarovsk, Russia \\ ${ }^{2}$ Pacific National University, Khabarovsk, Russia
}

\begin{abstract}
The paper presents the research results on produsing by the method of liquid-phase self-propagating high-temperature synthesis (SHS) the composite metal-matrix alloys intended for the obtaining of wearresistant coatings by electric spark deposition (ESD). Oxides $\mathrm{NiO}, \mathrm{Cr}_{2} \mathrm{O}_{3}$ and mineral concentrate $\mathrm{ZrO}_{2}$ were used as a melting charge. Alloys based on the Ni-Al system with aluminides of complex composition containing $\mathrm{Cr}$ and $\mathrm{Zr}$ were obtained by means of the alumothermic SHS reaction. Wear-resistant coatings were formed on steel 45 by the ESD method by means of the newly obtained alloys,. The maximum wear resistance of the coatings was obtained using the alloys containing $\mathrm{Cr}$ (wt\% 18) and $\mathrm{Zr}$ $(\mathrm{wt} \% 1.9)$.
\end{abstract}

\section{Introduction}

One of the main trends in the development of modern materials science is the production of new composite materials designed to improve the operational properties of various parts of machines and mechanisms. Intensive development of a new direction in science - "Surface Engineering" which is aimed at investigating the processes of modifying the materials surface, gave impact to a noticeable increase of publications in top-rated journals on the issue.

Methods of concentrated fluxes of energy (CFE) such as laser, plasma, explosion, etc. are now more and more often used worldwide for obtaining coatings. These methods include electric spark deposition (ESD), based on the electric spark erosion process between electrodes (cathode and anode) [1, 2]. Under the condition of predominant electrical erosion of the anode (applied material) with subsequent fixation of the anode material on the cathode (workpiece), a coating with unique properties is formed on the workpiece surface. The main advantages of the ESD method are the simplicity of the technological process of coating deposition, the possibility to use any conductive material as anode, and obtaining of highly adhesive coatings to the cathode.

However, up to the present time, the use of the ESD method in industrial production is limited because of high surface roughness of the coatings obtained; limited list of the anode

\footnotetext{
* Corresponding author: jenya_1992g@mail.ru
} 
materials created especially for ESD; insufficient knowledge of the physics of the electric spark process. Usually to obtain coatings by the ESD method hard alloys based on W and Ti carbides are used, which is conventional in metalworking.

Recently, the interest to the problem of obtaining anode materials intended especially for the ESD and powder metallurgy methods in particular has noticeably increased. The powder metallurgy method with all its advantages has a significant drawback - high cost of production technology. However, in this respect self-propagating high-temperature synthesis (SHS) is advanced and promising method of obtaining anode materials for ESD $[3,4]$.

The SHS method is subdivided into two types: solid-phase, when the process takes place in the solid phase; and liquid-phase when the resulting ingot is formed in one stage [5, 6]. In addition, the high solidification rate of the reacting products at SHS makes it possible to reduce the dendritic segregation of the metal and contributes to the formation of a finegrained structure. A large number of different alloys have been obtained by the liquid-phase SHS method. The use of oxides [7] and mineral concentrates in the melt charge at liquidphase SHS significantly increases the economic feasibility of the process of obtaining new anode materials for ESD.

$\mathrm{Ni}-\mathrm{Al}$ based composite materials as metal matrix are increasingly used in industrial production and more and more often become the subject of scientific research. Nickel aluminides, having high heat and wear resistance, are widely used in the creation of new composite materials intended for applying in aviation, automotive and power engineering.

To get a strengthening phase in composite metal-matrix alloys of Ni-Al system borides, carbides, nitrides are used, which are formed by adding rare metals ( $\mathrm{W}, \mathrm{Zr}$, etc.) into a melt charge of [8-10]. Until now traditional foundry technologies are widely used, though they are distinguished by multistage technological cycles and high cost in industrial production. The SHS method is devoid of the drawbacks of traditional technologies and therefore is promising in producing composite metal-matrix alloys.

The aim of this research work is to obtain composite materials based on Ni-Al system intended to be used for the formation of the ESD wear resistant coatings on steel.

\section{Methods and materials}

In the course of the experiments, we used anode materials from metal ingots, which were melted by the liquid-phase SHS method. The melt charge for metal-thermal smelting consisted of metal oxides (purity, wt\% - nickel oxide NiO-98.9, chromium oxide $\mathrm{Cr}_{2} \mathrm{O}_{3}$ 98.5) and calcium fluoride $\mathrm{CaF}_{2}$ (grade "Ch", technical purity) as a flux. The source of rare metal in the charge was the ore of the Algominsk deposit of the Russian Far East region, which includes up to $70 \mathrm{wt} \% \mathrm{ZrO}_{2}$ and a number of accompanying impurities (Fe, $\mathrm{Si}$ ). The reducing agent was aluminum-99.5 powder (average particle size $-50 \mu \mathrm{m}$ ). For the coating deposition we used samples of cathodes made of steel 45 , which is used in mechanical engineering to produce a number of machine parts operating under increased wear conditions.

ESD processing was carried out using an "IMEIL" installation, specially developed at the Institute. Operating parameters of electric spark pulses of this installation can be changed over a wide range. By changing the duration of the electric spark pulse $\left(t_{p}\right)$ and the duty cycle $\left(t_{c}\right)$, it is possible to change the pulse energy $\left(E_{i m p}\right)$ in a wide interval. During preliminary experiments, the optimal modes of the electric spark installation were established as follows: $\mathrm{t}_{\mathrm{c}}=50 \mu \mathrm{s}, \mathrm{t}_{\mathrm{p}}=40 \mu \mathrm{s}, \mathrm{E}_{\text {imp. }}=3.12 \mathrm{~J}$.

To obtain coatings by the ESD method, experiments are usually, carried out to determine $\Delta_{\mathrm{k}}$ and $\Delta_{\mathrm{a}}$ - the cathode gain and anode erosion, respectively, at each subsequent minute of ESD, up to the time $t_{x}$ - the threshold of brittle destruction of the coating (the 
processing time after which the cathode mass begins to decrease). The efficiency of the anode material is estimated on the basis of the material transfer coefficient $\left(\mathrm{K}_{\mathrm{p}}\right)$, which is equal to the ratio $\Delta_{\mathrm{k}} / \Delta_{\mathrm{a}}$.

In these experiments the coatings obtained from the composite materials were protected against oxidation by blowing the cathode surface with argon. When establishing the optimal modes of the ESD processing, we tried to ensure the minimum amount of oxides and cracks in the coating material. Wear resistance studies of the coatings were carried out according to the "ball - plane" scheme under dry friction conditions using a CALOTEST CSMI instrument and rotating corundum ball with a diameter of $20 \mathrm{~mm}$. Mass transfer and wear resistance were measured by the gravimetric method using a ShinkoDenshiHTR-220 CE electronic balance. Phase composition was determined on DRON-7 diffractometer (CuK radiation). Microhardness was investigated using a PMT-3M microhardness tester. Microstructure and micro X-ray spectral analysis were performed using HitachiSU-70 cWDS scanning electron microscope and EDS attachments.

\section{Results and discussion}

Metallothermal smelting was carried out in steel crucibles lined with refractory material. The prepared melt charge was mixed in a rotary mixer for 10 minutes and then loaded into the crucible. To compact the charge in the crucible a vibrating table was used, the vibration frequency of which was $100 \mathrm{~Hz}$, the vibration time was 5 minutes. The reaction was initiated by means of electric igniter from above. After arson, the reaction proceeded without external heating. After the completion of the SHS process and subsequent cooling of the crucible, the resulting product was extracted; it looked like a hard and porous cake from gray slag, corresponding to the size and shape of the crucible. The sinter having been destructed, a globular ingot with a sharply defined boundary between the metal of the ingot and the slag was found in its lower part. The formation of a sharp boundary between slag and metal of the ingot is an indirect sign of the formation of a dense, non-porous ingot. The ingots macrostructure was investigated in fractures using a binocular microscope MBS 10. The metal of the experimental melts appeared to be without slag inclusions, however the presence of sporadic small globular pores $(<1 \mathrm{~mm})$ should be noted. The melt charge was calculated basing on the formation of a NiAl matrix and an increase in the concentration of $\mathrm{Cr}$ and $\mathrm{Zr}$ in the ingots.

Table 1. Elements content in the obtained alloys

\begin{tabular}{|l|l|l|l|l|l|l|}
\hline \multirow{2}{*}{ Melt, № } & \multicolumn{6}{l}{ Elements content, wt.\%, } \\
\cline { 2 - 8 } & $\mathrm{Al}$ & $\mathrm{Si}$ & $\mathrm{Cr}$ & $\mathrm{Fe}$ & $\mathrm{Ni}$ & $\mathrm{Zr}$ \\
\hline 1 & 42,8 & - & 12,7 & 0,14 & 44,2 & - \\
\hline 2 & 29,18 & 2,1 & 12,8 & 0,2 & 53,8 & 1.6 \\
\hline 3 & 36,5 & 1,1 & 15,3 & 0,17 & 45,1 & 1.8 \\
\hline 4 & 25,5 & 1,4 & 18,1 & 0,15 & 52,9 & 1.9 \\
\hline
\end{tabular}

Table 1 shows the results of the elemental composition of the obtained ingots. As follows from the above given results, a monotonic increase in the concentration of $\mathrm{Cr}$ and $\mathrm{Zr}$ is observed in metal smelts. The absence of Si in metal smelt No. 1 can be explained by higher temperature of the SHS process of this smelt. Microstructure of the obtained alloys is shown in Figure 1. The grains dispersion in alloys No. 1 - No. 4 slightly decreases along side with concentration growth of $\mathrm{Cr}$ and $\mathrm{Zr}$ in the alloys, herewith the sizes of intergranular areas change. 

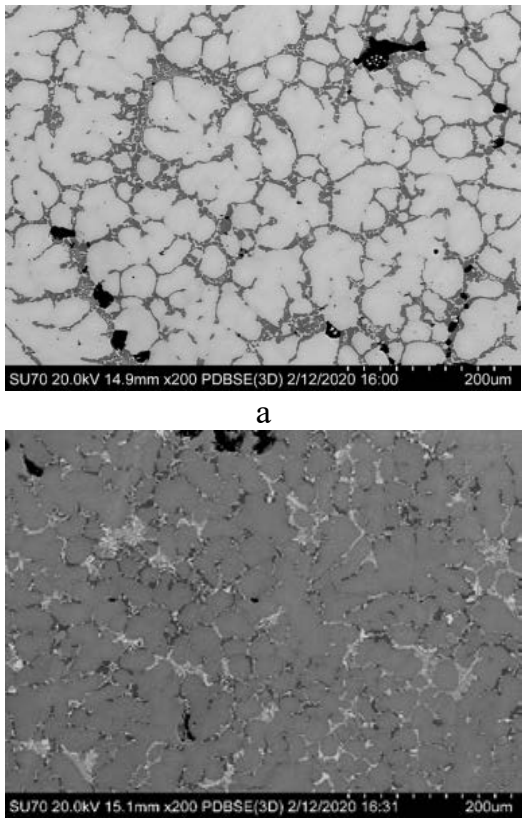

$\mathrm{c}$

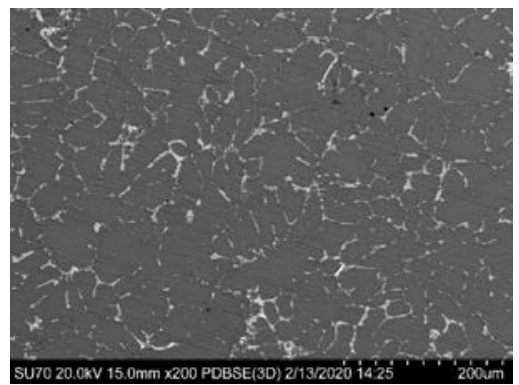

$\mathrm{b}$

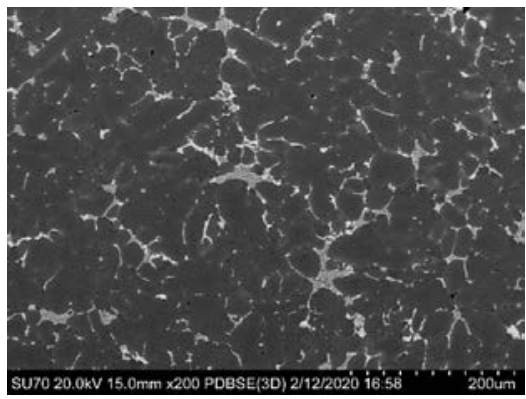

d

Fig. 1. Microstructure of the obtained alloys in the experimental smelts: a - No. 1; b - No. 2; c - No. 3; d - No. 4

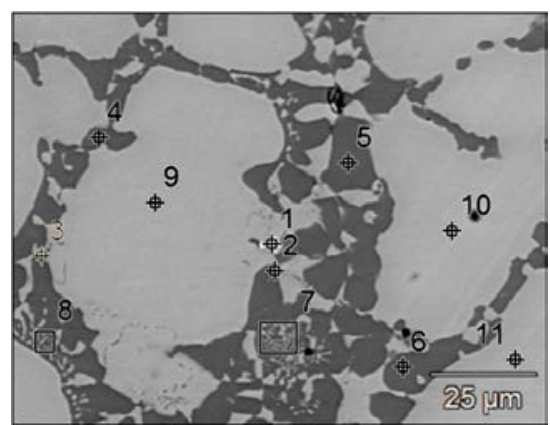

a

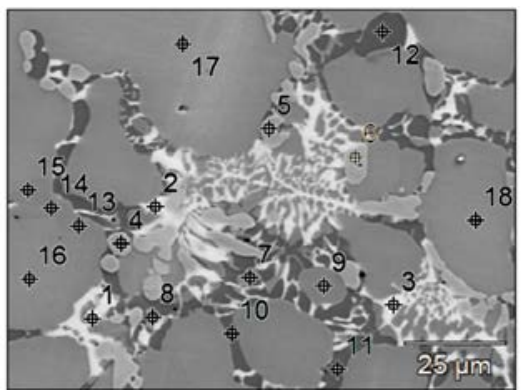

C

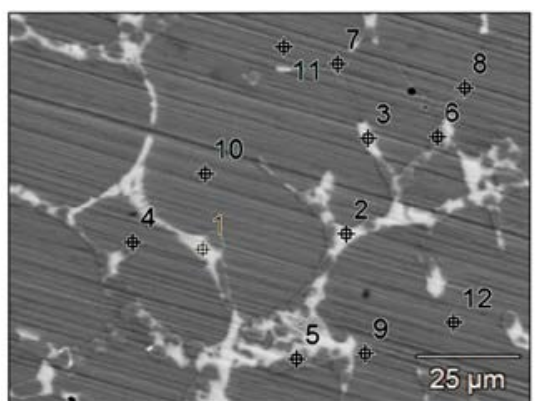

b

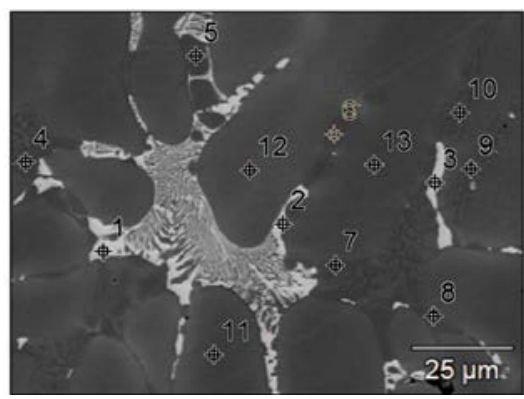

d

Fig. 2. Distribution of elements and points of micro-X-ray spectral composition in the structural components of the obtained alloys in the experimental smelts: a - No. 1; b - No. 2; c - No. 3; d - No. 4 
Figure 2 shows the points of the X-ray micro-spectral analysis. The results of the X-ray micro-spectral analysis are summarized in Table 2 . The data were averaged at the points where these did not differ significantly.

Table 2. Elements content of in the structural components of the alloys of smelts a b c d

\begin{tabular}{|c|c|c|c|c|c|}
\hline \multirow[t]{2}{*}{ Analysis points } & \multicolumn{5}{|c|}{ Elements content, at. \% } \\
\hline & $\widehat{A l}$ & $\mathrm{Si}$ & $\mathrm{Cr}$ & $\mathrm{Ni}$ & $\mathrm{Zr}$ \\
\hline \multicolumn{6}{|l|}{ Figure 2,, a } \\
\hline 1 & 9.11 & - & 47.93 & 8.02 & 28.85 \\
\hline 2 & 33.68 & - & 35.50 & 12.89 & 15.61 \\
\hline 3 & 58.16 & - & 7.31 & 32.89 & 1.44 \\
\hline $4-6$ & $61.33-62.31$ & - & $35.06-36.16$ & $2.49-2.63$ & - \\
\hline 7,8 & $60.77-61.94$ & - & $27.64-28.27$ & $9.80-11.59$ & - \\
\hline $9-11$ & $58.06-58.42$ & - & $3.48-4.91$ & $36.76-38.10$ & - \\
\hline \multicolumn{6}{|l|}{ Figure $2, \mathrm{~b}$} \\
\hline 1 & 47.50 & 3.25 & 8.72 & 24.65 & 15.88 \\
\hline 2 & 45.88 & 3.71 & 12.70 & 19.36 & 18.02 \\
\hline 3 & 47.67 & 1.98 & 10.50 & 21.37 & 18.48 \\
\hline $4-6$ & $4.56-5.03$ & $20.52-20.70$ & $72.50-73.25$ & $1.37-1.87$ & - \\
\hline $7-9$ & $17.62-21.49$ & $2.90-6.02$ & $67.60-72.19$ & $3.65-6.86$ & - \\
\hline $10-12$ & $52.43-53.31$ & - & $3.31-4.07$ & $42.80-43.52$ & - \\
\hline \multicolumn{6}{|l|}{ Figure 2, c } \\
\hline 1 & 49.00 & 1.26 & 17.04 & 16.28 & 16.42 \\
\hline 2 & 50.30 & 1.00 & 10.70 & 18.28 & 19.72 \\
\hline 3 & 51.14 & 0.99 & 9.59 & 18.44 & 19.83 \\
\hline $4-6$ & $2.87-3.13$ & $22.29-21.80$ & $74.20-74.64$ & $0.67-0.85$ & - \\
\hline $7-9$ & $54.61-55.08$ & - & $8.56-11.50$ & $33.89-36.36$ & - \\
\hline $10-12$ & $56.42-56.75$ & $1.41-1.61$ & $37.88-39.51$ & $2.17-4.29$ & - \\
\hline $13-15$ & $55.03-55.80$ & - & $6.77-8.71$ & $35.49-37.87$ & - \\
\hline $16-18$ & $53.93-54.33$ & - & $3.33-4.34$ & $41.33-42.75$ & - \\
\hline \multicolumn{6}{|l|}{\begin{tabular}{|l|} 
Figure 2, d \\
\end{tabular}} \\
\hline 1 & 2.51 & 20.77 & 3.48 & 54.22 & 19.02 \\
\hline 2 & 2.92 & 19.98 & 4.06 & 53.77 & 19.27 \\
\hline 3 & 1.88 & 21.22 & 5.92 & 53.82 & 17.16 \\
\hline $4-8$ & $3.78-1.50$ & $5.92-6.80$ & $81.32-84.83$ & $6.87-8.98$ & - \\
\hline 9,10 & $7.87-10.97$ & $4.63-5.08$ & $66.70-72.14$ & $14.91-17.71$ & - \\
\hline $11-13$ & $41.54-42.49$ & - & $6.45-7.26$ & $51.20-51.96$ & - \\
\hline
\end{tabular}

The intermetallic matrix in alloys No. 1-No. 4 has a NiAl phase composition but with a different ratio of the components, which is consistent to the phase diagram. The NiAl phase formation was established basing on the results of microhardness analysis, the values of which were compared with X-ray phase analysis and those given in the literature. The ratio of the components in the grains of NiAl phase matrix was established as follows: No. 1 $\mathrm{NiAl}_{1.5}$ (points 9-11, Figure 2, a); No. 2 - $\mathrm{NiAl}_{1.2}$ (points 10-12, Figure 2, b); No. 3 - $\mathrm{NiAl}_{1.3}$ (points 16-18, Figure 2, c); No. $4-\mathrm{Ni}_{1.2} \mathrm{Al}$ (points 11-13, Figure 2, d). As can be seen from the results of the analysis the concentration of aluminum prevails in the alloys No. 1-No. 3, and only in alloy No. 4 there is a slight predominance of $\mathrm{Ni}$ in the NiAl phase. In the composition of all the alloys, NiAl phase is alloyed with $\mathrm{Cr}$ (3.3 - 4.9 at.\%), moreover its 
increased concentration is registered in alloy No. 4 (6.4 - 7.2 at.\%) and also in alloy No. 3 (points 13-15 and 7-9 in the form of separate sections and inclusions, Figure 2, c).

Zirconium in alloys is located along the grain boundaries and is a part of the phases of $\mathrm{Ni}-\mathrm{Al}-\mathrm{Cr}$ system, and in this case Al prevails in the alloys of smelts No. 1-No. 3 (points 13 , Figures 2, a, b, c), but in the alloy of smelt No. 4 this phase contains $>50$ at. $\% \mathrm{Ni}$ and a much higher Si concentration (points 1-3, Figure 2, d).

The process of obtaining coatings was carried out in accordance with the accepted procedure. Figure 3 shows the dependences of mass changes of the cathodes during the coatings formation using alloys No. 1 - No. 4. Maximum mass transfer is achieved with alloy No. 4, and minimum - with alloy No. 2. It should be noted, that alloys No. 3 and No. 4 had the same mass transfer up to 6 minutes of electric spark treatment. However, at further processing the coating of alloy No. 3 began to break down brittle. The evaluation of the efficiency of using the anode material for the formation of coatings by the ESD method was carried out using the mass transfer coefficient $\mathrm{Kp}$. The graph of Kp change depending on the processing time and on the use of alloys No. 1 - No. 4 is shown in Figure 3, b.

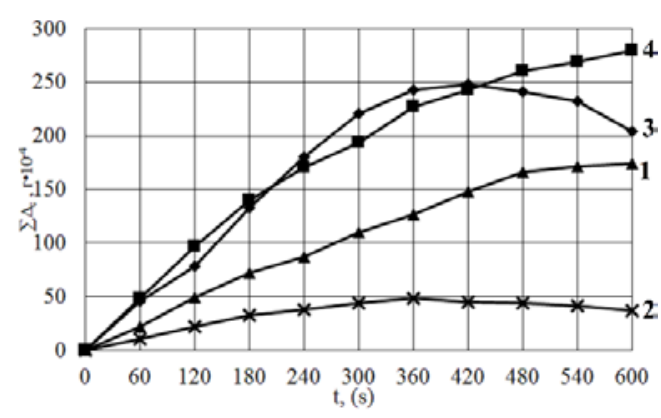

a

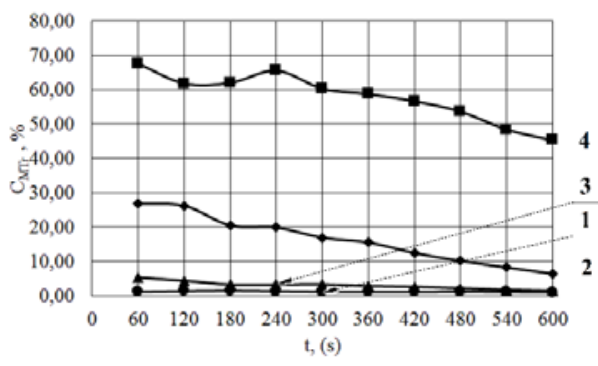

b

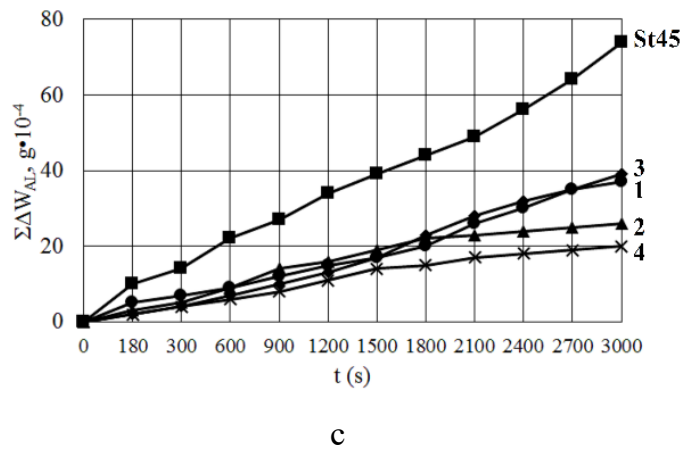

Fig. 3. Mass change of cathode, mass transfer coefficient and wear resistance of coatings obtained when using alloys No. 1 - No. 4: a - mass change of cathodes during ESD with alloys No. 1 - No. 4; b - change in Kp during the coating process; c - wear resistance of coatings obtained with alloys No. 1 No. 4

Alloy No. 4 proved to be the most effective anode material of all the alloys used in the experiment for the formation of wear resistant coatings by the ESD method. The metallographic assessment of the coatings obtained by the experimental alloys was carried out on thin cross sections. As a result of this analysis, it was found that all the coatings contained transverse microcracks. However, the coatings formed by alloy No. 4 turned to be more uniform in thickness and had fewer microcracks. When testing, coatings formed by alloys No. 1 and No. 3 demonstrated the minimum value of wear resistance, but still in comparison with steel 45 without coatings it increased up to 2 times, which allows the use 
of experimental alloys for the formation of wear-resistant coatings. The maximum wear resistance value was recorded when testing coatings formed by alloy No. 4 (Figure 3, b). In this case the coating wear resistance increased more than 3 times.

Designation of curves on the graphs: 1 - No. 1, 2 - No. 2, 3 - No. 3, 4 - No. 4

\section{Conclusions}

Thus, based on the results obtained, a number of conclusions can be drawn:

1. Alloyed anode materials based on nickel aluminides intended for making wearresistant coatings by ESD are possible to be melted by the liquid-phase SHS method.

2. The best wear resistant coatings were obtained when using the alloy containing the maximum concentration of alloying elements $\mathrm{Cr}(\mathrm{wt} \% 18)$ and $\mathrm{Zr}(\mathrm{wt} \% 1.9)$.

3. Maximum concentration of $\mathrm{Ni}$ is found in the base grains $(\mathrm{NiAl})$ with the maximum content of alloying elements $\mathrm{Cr}$ and $\mathrm{Zr}$ in the alloy, causing the increase of its plasticity.

\section{References}

1. Xie, Y.J.;Wang, M.C. Microstructural morphology of electrospark deposition layer of a high gamma prime superalloy. Surf. Coat. Technol., 201, 691-698, (2006).

2. Reynold, J.L.; Holdren, L.R.; Brown, L.E. Electro-Spark Deposition. Adv. Mater. Process., 161, 35, (2003).

3. Oniashvili, G.S.H.; Aslamazashvili, Z.G.; Zakharov, G.V.; Tavadze, G.F.; Chikhradze, M.N.; Dzigrashvili, T.A.; Berner, A. SHS of fine-grained ceramics containing carbides, nitrides, and borides. Int. J. Self Propag. High Temp. Synth., 22, 185-188, (2013).

4. Shekari, M.; Adeli, M.; Khobzi, A.; Kobashi, M.; Kanetake, N. Induction-activated self-propagating, high-temperature synthesis of nickel aluminide. Adv. Powder Technol., 28, 2974-2979, (2017).

5. Gostishchev, V.V.; Astapov, I.A.; Medneva, A.V.; Ri, H.; Khimukhin, S.N. Fabrication of Alloyed Aluminum Nickelides by Metallothermy of Metals Oxides. Russ. J. Non-Ferr. Met., 57, 41-46, (2016).

6. Gostishchev, V.V.; Astapov, I.A.; Seredyuk, A.V.; Khimukhin, S.N.; Ri, H. HighTemperature Synthesis of Composites Based on Nickel Aluminides. Inorg. Mater., 4, 419-422, (2016).

7. Lapshin, O.V.; Ovcharencko, V.E.; Boyangin, E.N. Thermokinetic and Thermophysical Parameters of High-Temperature Synthesis of Intermetallide Ni3Al by Thermal Shock of a Powder Mixture of Pure Elements. Combust. Expl. Shock Waves, 38, 430-434, (2002).

8. Bochenek, K.; Basista, M. Advances in processing of NiAl intermetallic alloys and composites for high temperature aerospace applications. Prog. Aerosp. Sci., 79, 136146, (2015).

9. Guo, J.;Wang, Z.; Sheng, L.; Zhou, L.; Yuan, C.; Chen, Z.; Song, L.Wear properties of NiAl based materials. Prog. Nat. Sci., 22, 414-425, (2012).

10. Bhaskar, M.S. Quantitative phase field modelling of precipitate coarsening in Ni-AlMo alloys. Comp. Mat. Sci., 146, 102-111, (2018). 